\title{
Using daily newspapers to develop professional literacy - a descriptive study
}

This article was published in the following Dove Press journal:

Advances in Medical Education and Practice

3 May 2013

Number of times this article has been viewed

\section{Kerry Wilbur}

College of Pharmacy, Qatar University, Doha, Qatar
Correspondence: Kerry Wilbur College of Pharmacy, Qatar University, PO Box 2713, Doha, Qatar Tel +974 4403558 I

Fax+97444035 55।

Email kwilbur@qu.edu.qa
Background: An orientation to the professional landscape is necessary for novices of any health discipline. We describe an assignment aimed to develop the professional literacy of pharmacy students within their local Middle Eastern context.

Methods: "Pharmacy and Health Care" is a course designed to introduce first-year students to both historic and contemporary pharmacist roles and responsibilities and to the position of pharmacy within a health care system. An assignment asked students to identify a health-related article recently reported by one of the domestic newspapers in order to exhibit the students' ability to conceptualize how pharmacists fit into the described health context.

Results: The exercise was assigned over three consecutive academic years. A majority of the students $(36 / 60 ; 60 \%)$ chose articles reported in one of the three English-language dailies; stories were primarily characterized as Qatar health-related current events or news items $(44 / 60 ; 73 \%)$. The pharmacy students felt the assignment encouraged reading and an appreciation of current pharmacist roles and future opportunities in Qatar health care.

Conclusion: A newspaper assignment designed to develop professional literacy would be of benefit in early training years in health care professional degree programs elsewhere in the world; the result would orient students to expected positions in local health care settings and would help envision role expansion.

Keywords: pharmacy, health professional education, newspaper

\section{Introduction}

The State of Qatar is an Arab emirate occupying a small peninsula in the Persian Gulf with a (predominantly expatriate) population of 1.9 million people. This gas- and oil-rich nation has committed to building a knowledge-based economy, directing a number of investments into nonenergy sectors, including modernization of its health care infrastructure and the expansion of domestic educational opportunities. ${ }^{1}$ Until recently, there has been little local training opportunities for health professionals, including physicians, nurses, and other allied health providers. The Canadian-accredited College of Pharmacy at Qatar University, the first and only pharmacy degree program in the country, graduated its small $(n=18)$ inaugural class in 2010.

"Pharmacy and Health Care" is a series of two, one-semester courses, designed to introduce first-year students both to historic and contemporary pharmacist roles and responsibilities and to the position of pharmacy within the health care system. Lecture content and assignments sample from a broad range of related topics designed to inform current trends and challenges in pharmacy practice and health care, including 
the influences of drug marketing and media on prescribing, and pharmacist participation in multidisciplinary care.

Professional literacy may be defined as an appreciation of the landscape of one's profession coupled with its explicit and implicit structures and strictures. ${ }^{2}$ An orientation to the professional landscape is necessary for novices of any health discipline; it is all the more important for pharmacists in the Middle East where contemporary patient-oriented practice is in a state of relative infancy. ${ }^{3,4}$ Graduating pharmacy students in Qatar will be challenged to overcome documented levels of low public expectations, while also paradoxically encountering tremendous opportunities for assuming leadership positions as health care facilities proliferate and existing infrastructures mature in sophistication and scope. ${ }^{5,6}$

One tool for teaching contemporary health issues and exploring their relationships with pharmacy practice is the local newspaper. Several theoretical frameworks have been proposed for the utility of newspapers, and other media, as multifunctional learning resources. ${ }^{7,8}$

Educators have employed published dailies as instruments for instructional purposes as diverse as developing first and second language literacy (reading, spelling, and writing abilities) and investigating health-topic framing through detailed media content analysis. ${ }^{9-12}$ Teaching with newspapers not only promotes critical-thinking skills and vocabulary acquisition, it can also illustrate how one's profession is portrayed; it consequently conveys the important role of various media in forming and reinforcing popular attitudes that may influence practice. ${ }^{13}$ Unfortunately, little experience using newspapers to develop such abilities and insights has been published in health education. ${ }^{14}$ How can undergraduate health professionals in their early curricular years acquire practical understanding of their future roles? We describe an assignment aimed to develop the professional literacy of pharmacy students within their local Middle Eastern context.

\section{Methods}

At the onset of the semester, students were asked to identify a health-related article recently reported by one of the domestic newspapers; in Qatar, three English and three Arabic language dailies are published. Local stories were preferred, but health-related stories that were generated internationally and were covered in the Qatar paper were considered acceptable. The article could be obtained from the print or online edition and was ultimately assigned to one of four categories: (1) Qatar health-related current event or news item; (2) a summary of a drug or disease for the reader's educational purposes authored in Qatar or the Middle East; (3) a health-related current event or news item originating from outside Qatar; or (4) a summary of a drug or disease generated outside the Middle East but reprinted in Qatar. Throughout the semester, each student had a 5-minute in-class presentation to achieve the following: (1) display and summarize the article; (2) describe how its health-oriented content related to pharmacists; and (3) opine how they believed it could impact Qatar pharmacy practice now or in the future. The assignment was worth $5 \%$ of the students' final course grade.

The instructional design of the assignment was based on the concepts of constructivism. ${ }^{15,16}$ In our exercise, the learner extracts the necessary information from the content presented in the self-selected newspaper article, so as to complement the insufficient domain-specific knowledge the learner had, and to reflect and construct a mental model. The assignment's intended learning outcomes for the pharmacy students were threefold: (1) enhance reading fluency and demonstrate comprehension of specific information; (2) increase familiarity with health-related issues reported in the lay media; and (3) exhibit ability to conceptualize and articulate how pharmacists fit (explicitly or implicitly) into the health context of the lay media report. At the end of the semester, each student completed a mandatory course evaluation that included an opportunity to provide feedback related to this specific assignment. These student comments were compiled into a singular document and content subjected to exploratory textual analysis to identify, compare, and contrast possible themes. ${ }^{17}$ NVivo $9{ }^{\circledR}$ (NVivo $9^{\circledR}$; QSR International, Melbourne, Victoria, Australia) qualitative data analysis software was employed.

\section{Results}

The exercise was assigned over three consecutive academic years to 60 students $(n=21$ in 2009; $n=14$ in 2010; $\mathrm{n}=25$ in 2011). Examples of newspaper articles presented by the undergraduate pharmacy students are presented in Table 1. A majority of students $(36 / 60,60 \%)$ chose articles reported in one of the three English language dailies. These stories were primarily characterized as Qatar health-related current events or news items $(n=44)$, followed by health information pieces authored locally $(n=6)$. Current events and health information articles originating abroad were each summarized by five students. Only 5\% $(n=3)$ and $10 \%(n=6)$ were about or authored by pharmacists or were medication-related, respectively. Consistently each year, 
Table I Sample health-related newspaper articles selected by undergraduate pharmacy students

\begin{tabular}{|c|c|c|}
\hline Category & Examples & Newspaper/date \\
\hline \multirow[t]{10}{*}{$\begin{array}{l}\text { Qatar health-related current } \\
\text { event or news item }\end{array}$} & $\begin{array}{l}\text { Rates of herbal drug use among a sample of } 45 \text { pregnant } \\
\text { woman in Qatar (report from Jordan medical conference) }\end{array}$ & Al Raya (Arabic) 03/II \\
\hline & Opening of Virgin ${ }^{\circledR}$ stem-cell bank in Doha & Gulf Times (English) 06/10 \\
\hline & Supreme Council of Health project for patients to locate & Peninsula (English) 02/II \\
\hline & through their mobile phones physicians who are accepting & \\
\hline & new clients & \\
\hline & Lack of child-proof containers for medications dispensed & Gulf Times (English) 06/II \\
\hline & in Qatar (report from study) & \\
\hline & Prevalence of kidney failure in Qatar (report from study) & \\
\hline & Hamad General Hospital completes obesity surgery on & Al Raya (Arabic) 04/09 \\
\hline & 500th patient & Gulf Times (English) 03/II \\
\hline Health-related summary or & Depression management and antidepressant use in Qatar & Al Raya (Arabic) 03/II \\
\hline opinion-piece authored in & (interview with a psychiatrist) & \\
\hline \multirow[t]{2}{*}{ Qatar or the Middle East } & How to protect oneself from the ill effects of health from & The Peninsula (English) 03/II \\
\hline & change in weather (interview with an emergency physician) & \\
\hline International health-related & New drug for sleeping sickness management in Africa & Al Raya (Arabic) 04/I0 \\
\hline \multirow[t]{2}{*}{ current event or news item } & (reprinted report from Scotland) & \\
\hline & Swine flu update (reprinted report from Reuters) & Qatar Tribune (English) 02/09 \\
\hline Health-related summary or & Importance of smoking cessation posthospitalization for $\mathrm{MI}$ & Al Sharq (Arabic) 03/10 \\
\hline \multicolumn{3}{|l|}{ opinion piece authored outside } \\
\hline the Middle East, but reprinted & Obesity and its impact on aging and life expectancy & Al Watan (Arabic) 03/09 \\
\hline in Qatar & & \\
\hline
\end{tabular}

Abbreviation: MI, myocardial infarction.

students suitably identified - during their presentation or when prompted by the instructor - the potential implications of the lay media health report on current or future Qatar pharmacy practice. For example, the importance of pharmacist roles in ensuring appropriate prescription drug use (antidepressant management), in promoting non-pharmacologic or lifestyle interventions (obesity surgery), in understanding of disease and modern treatments and preventative interventions (stem cell therapy, swine flu immunization), and in supporting patient self-selection of medication and goal setting (smoking cessation, herbal use in pregnancy), were all invoked using the selected articles (Table 1).

When opinions regarding students' perceived utility of this exercise were annually sought in the anonymous final course evaluation, the overwhelming sentiment was favorable $(59 / 60,98.3 \%)$, with persistent themes expressed each year. The pharmacy students felt the assignment encouraged reading: “... it gave me the first push to start reading about something related to pharmacy"; “... during my reading I learned a lot and I am still reading in my spare time." It also promoted research and communications skills: “... it helped me a lot in my searching skills because I did not used to read anything related to science in a newspaper"; “... it assessed our abilities to summarize and paraphrase and give a small presentation." They gained appreciation for how their coursework will apply to skills required of them as future health professionals: "I liked the newspaper assignment because it allows the students to see the role of pharmacy in health care in real life." The assignment was important for them to understand how pharmacists can contribute to health care and gave them the feeling of having more information about their career choice: "... we saw what are the future changes and plans towards developing health and enhancing pharmacist roles in Qatar." Many appreciated the opportunity to learn more about health care activities in Qatar: "I personally learned from the activity a lot of information about health in Qatar (studies, campaigns, events)"; "I noticed that health care is really improving in Qatar and that the pharmacist role will be appreciated with time." The one student who rated the assignment negatively opined that the reach of newspapers is limited and other media would be more effective to reach a larger audience.

\section{Discussion}

This assignment designed to orient first-year undergraduate students to pharmacist roles in health care achieved its intended learning outcomes. First, it is generally viewed that contemporary Middle Eastern Arab youth are not prolific readers, irrespective of language (eg, reading materials in native Arabic or English as a second language). ${ }^{18,19}$ Our students often acknowledged low extracurricular reading 
activities and welcomed this opportunity to explore a non-traditional course resource. While English is the language of instruction in the Qatar University College of Pharmacy, students' first language is overwhelmingly Arabic, and so it is unexpected that most articles chosen for summary and scrutiny were from the English newspapers. It is unclear if this can be attributed to student preference, whether a wider selection of health-related stories is reported in English, or if the articles are somehow more accessible. Illustrating the value of health- and practice-issue reading with structured opportunities for undergraduate pharmacy students is also a useful vehicle to foster self-directed learning and promote skills to keep up with evidence-based literature necessary for health professionals. ${ }^{20}$

Second, regardless of the source language, pharmacist familiarity with lay media is essential for patient-oriented health care. The Internet and various social media have now joined television and newspapers as alternate patient sources for health information, particularly among educated young adults. $^{21,22}$ Pharmacists not only need to be familiar with popular information to which their patients may be exposed (or actively seek out), they must be able to guide their patients' interpretation and application of the information, especially as it pertains to rational and safe medication use. ${ }^{23}$

Third, the majority of articles chosen were local health stories. The students were able to learn more about health care-related initiatives in Qatar and conceive domestic opportunities for pharmacists and pharmacy practice. As one student put it, "it has made us aware of the nature of work in a health care environment and our chances in Qatar ahead."

While it is important for undergraduate pharmacy students to develop professional literacy, it cannot be underemphasized that this understanding must not only comprise traditional practice, but also accommodate a vision for contemporary patient-oriented roles that is not restricted by prevailing cultures. Even in countries with existing high social acceptance of the pharmacist position in health care, potential barriers to advancing pharmacy practice have been demonstrated among pharmacists who still principally place themselves in product-centered roles. ${ }^{24,25}$ This exercise compels undergraduate students to recognize existing practice while creating inferences for future responsibilities, which may predispose and motivate students to assume the challenges of advancing beyond accepted roles. By promoting student-generated construction of new cognitive models on top of the current understanding, the assignment adheres to the fundamental tenet of constructivism. ${ }^{26}$
This is the first documented experience of newspaper use as an instructional tool to guide pharmacy student reflection and formation of professional identities. These findings may stimulate future systematic evaluation of pharmacy practice portrayal in the press. Such reviews among health professions have largely been the domain of nursing and have focused on dramatic depictions. ${ }^{11,27,28}$ Pharmacy practice could benefit from formal scrutiny of media messages and their potential impact on formation of public perceptions and expectations. ${ }^{29,30}$

Some limitations to the portability of anticipated student learning outcomes of this newspaper assignment merit mention. This exercise would be expected to have less impact in countries where the public profile of pharmacy practice is high, and therefore, undergraduates have a greater exposure to and understanding of pharmacist roles at baseline. In the future, we may observe a blunted impact within our own curriculum as the population of undergraduates becomes better acquainted with pharmacy as a discipline. This assignment's learning objective for students to draw pharmacy practice inferences from information in lay media text may not be feasible for programs in developing countries where the volume of domestic health care reporting in newspapers is low.

\section{Conclusion}

A newspaper assignment designed to develop professional literacy has been successfully implemented in a first-year undergraduate pharmacy course in a Middle East College of Pharmacy. This exercise would be of benefit in early training years in other health professional degree programs elsewhere in the world; the result would orient students to expected positions in local health care settings and would help envision role expansion.

\section{Disclosure}

The author reports no conflicts of interest in this work.

\section{References}

1. Qatar National Health Strategy. Qatar National Health Strategy 2011-2016. Caring for the future [homepage on the Internet]. Qatar: Qatar National Health Strategy; 2013. Available from: http://www.nhsq. info/home. Accessed March 1, 2013.

2. University of Arizona Library. Slavic information literacy for students, scholars, and educators [webpage on the Internet]. Tucson, AZ: University of Arizona Library; 2013. Available from: http://intranet. library.arizona.edu/users/brewerm/sil/prof/index.html. Accessed March 1, 2013.

3. Kheir N, Zaidan M, Younes H, El Hajj M, Wilbur K, Jewesson PJ. Pharmacy education and practice in 13 Middle Eastern countries. Am J Pharm Educ. 2008;72(6):133. 
4. Kheir N, Al-Saad D, Al-Naimi S. The status of pharmaceutical care in the Middle East. [Poster]. Proceedings of the 2012 Dubai International Pharmaceuticals and Technologies Conference and Exhibition (DUPHAT); March 12-14, 2012; Dubai, United Arab Emirates.

5. El Hajj MS, Salem S, Mansoor H. Public's attitudes towards community pharmacy in Qatar: a pilot study. Patient Prefer Adherence. 2011;5:405-422.

6. Ithmar Capital. Expand, Consolidate and Support: Meeting the GCC Healthcare Challenge 2050. London, UK: Dow Jones Private Equity 2009. Available from: http://news.ithmar.com/IthmarHealthcarePaper. pdf. Accessed March 1, 2013.

7. Gardner JN, Sullivan BL. The national newspaper as a tool for educational empowerment: origins and rationale [webpage on the Internet]. The New York Times. New York, NY: The New York Times; 2004. Available from: http://www.nytimes.com/ref/college/faculty/ coll_mono_gard.html. Accessed March 1, 2013.

8. Hasan EHR. Instructional Design and Media Selection [dissertation]. Enschede, Netherlands: Twente University; 2001.

9. Knowlton SR, Barefoot BO, editors. Using national newspapers in the college classroom (monograph number 28). In: National Resource Center for the First-Year Experience and Students in Transition. Resources to Improve Teaching and Learning. Columbia, SC: University of South Carolina; 1999.

10. Olivares RA. Using the Newspaper to Teach ESL Learners. Newark, DE: International Reading Association; 1993.

11. Martinson BE, Hindman DB. Building a health promotion agenda in local newspapers. Health Educ Res. 2005;20(1):51-60.

12. Carlsson JR, Renberg T, Sporrong SK. Drug experts of the future, today? - depiction of the pharmacist profession in Swedish professional and lay print media. Res Social Adm Pharm. 2012;8(2):133-144.

13. Johnson PH, Johnson RD. Teaching cotemporary health issues using a daily newspaper. In: American Alliance for Health, Physical Education, Recreation and Dance National Convention and Exposition. Chicago, IL; 2005 Apr 12-16.

14. Duffy TM, Jonassen DH. Constructivism: new implications for instructional technology. Educational Technology. 1991;31(5):7-12.

15. Kozma RB. Learning with media. Review of Educational Research. 1991;61(2):179-212.

16. Semiu B. Promotion of newspapers as a supplementary teaching and learning resource for quality education. Journal of Library Educational Media and Information Studies (JOLEMIS). 2010;1(1):51-66.
17. Bernard HR, Ryan G. Text analysis: qualitative and quantitative methods. In: Bernard HR, editor. Handbook of Methods in Cultural Anthropology. Walnut Creek, CA: Altamira Press; 1998:595-645.

18. United Nations Development Programme, Arab Fund for Economic and Social Development. Arab Human Development Report: Building a Knowledge Society. New York, NY: United Nations Publications; 2003.

19. Next Page Foundation. What Arabs Read [webpage on the Internet]. Sofia, Bulgaria: Next Page Foundation. Available from: http://www. npage.org/article63.html. Accessed March 1, 2013.

20. Tunney MM, Bell HM. Self-directed learning: preparing students for lifelong learning. Pharmacy Education. 2011;11(1):12-15.

21. Hogue MC, Doran E, Henry DA. A prompt to the web: the media and health information seeking behaviour. PLOS ONE. 2012;7(4):e34314.

22. Smith D. Health care consumer's use and trust of health information sources. J Communic Healthc. 2011;4:200-210.

23. Cain J, Romanelli F, Fox B. Pharmacy, social media, and health: Opportunity for impact. J Am Pharm Assoc (2003). 2010;50(6): 745-751.

24. Rosenthal MM, Breault RR, Austin Z, Tsuyuki RT. Pharmacists' selfperception of their professional role: insights into community pharmacy culture. J Am Pharm Assoc (2003). 2011;51(3):363-367.

25. Al Hamarneh YZ, Rosenthal M, McElnay JC, Tsuyuki RT. Pharmacists' perceptions of their practice: a comparison between Alberta and Northern Ireland. Int J Pharm Pract. 2012;20(1):57-64.

26. Kang LO, Brian S, Ricca B. Constructivism in pharmacy school. Currents in Pharmacy Teaching and Learning. 2010;2:126-130.

27. Buresh B, Gordon S. Taking on the TV shows. Am J Nurs. 1995; 95(11):18-20.

28. Takase M, Kershaw E, Burt L. Does public image of nurses matter? J Prof Nurs. 2002;18(4):196-205.

29. Guirguis LM, Chewning BA. Role theory: literature review and implications for patient-pharmacist interactions. Res Social Adm Pharm. 2005;1(4):483-507.

30. Kline KN. A decade of research on health content in the media: the focus on health challenges and sociocultural context and attendant informational and ideological problems. J Health Commun. 2006; 11(1):43-59.
Advances in Medical Education and Practice

\section{Publish your work in this journal}

Advances in Medical Education and Practice is an international, peerreviewed, open access journal that aims to present and publish research on Medical Education covering medical, dental, nursing and allied healthcare professional education. The journal covers undergraduate education, postgraduate training and continuing medical education

\section{Dovepress}

including emerging trends and innovative models linking education, research, and healthcare services. The manuscript management system is completely online and includes a very quick and fair peer-review system. Visit http://www.dovepress.com/testimonials.php to read real quotes from published authors. 